\title{
RELAÇÃO ENTRE CONDIÇÕES DE TRABALHO E SAÚDE DO ENFERMEIRO EMERGENCISTA
}

\section{RELATION BETWEEN WORKING AND HEALTH CONDITIONS OF THE EMERGENCY NURSE}

\section{RELACIÓN ENTRE CONDICIONES DE TRABAJO Y SALUD DEL ENFERMERO EMERGENCIAL}

\author{
Sara Gabrielle da Cruz Soares ${ }^{1}$, Mayara Regis Sena Gomes ${ }^{2}$, Mariana de Oliveira Araújo ${ }^{3}$
}

Como citar esse artigo: Soares SGC; Gomes MRS; Araújo MO. Relação entre condições de trabalho e saúde do enfermeiro emergencista. Rev Enferm Atenção Saúde, v. 9, n. 2, 95-110, 2020. DOI: 10.18554/reas.v9i2.3553

\section{RESUMO}

Objetivo: caracterizar as condições de trabalho dos enfermeiros emergencistas no cenário brasileiro e identificar como essas condições influenciam na saúde desses trabalhadores. Método: revisão integrativa, com levantamento online realizado em junho de 2020 no portal da Biblioteca Virtual em Saúde, nas Bases de Dados Literatura Latino-Americana e do Caribe em Ciências da Saúde e Banco de Dados em Enfermagem, usando os descritores: condições de trabalho AND enfermeiros AND emergência. Obteve-se 16 artigos, os quais foram analisados por meio da Análise de Conteúdo Temática. Resultados: as condições de trabalho dos enfermeiros emergencistas têm sido caracterizadas pela existência de espaço físico inadequado, longas jornadas de trabalho, falta de insumos e recursos humanos, o que repercute negativamente na saúde desses profissionais. Conclusão: os enfermeiros emergencistas no Brasil estão expostos a condições de trabalho que foram caracterizadas como desfavoráveis e precarizadas, as quais repercutem diretamente e negativamente na saúde desses profissionais.

Descritores: Condições de Trabalho; Enfermeiras e Enfermeiros; Emergências.

\begin{abstract}
Objective: to characterize the working conditions of emergency nurses in the Brazilian scenario and to identify how these conditions influence the health of these workers. Method: integrative review, with online survey conducted in June 2020 on the Virtual Health Library portal, in the Latin American and Caribbean Literature in Health Sciences Databases and Nursing Database, using the descriptors: working conditions AND nurses AND emergency. 16 articles were obtained, which were analyzed by means of Thematic Content Analysis. Results: the working conditions of emergency nurses have been characterized by the existence of inadequate physical space, long working hours, lack of inputs and human resources, which has a negative impact

\footnotetext{
${ }^{1}$ Enfermeira Graduada pela Universidade do Estado da Bahia (UNEB), Campus VII, Senhor do Bonfim-BA, Pósgraduada em Emergência e UTI (UNEB, Campus VII, Senhor do Bonfim-BA), Pós-graduada em Enfermagem do Trabalho pela Faculdade Venda Nova do Imigrante - FAVENI.

${ }^{2}$ Enfermeira Graduada pela Universidade Jorge Amado (UNIJORGE), Pós-graduada em Emergência e UTI (UNEB, Campus VII, Senhor do Bonfim-BA), Pós-graduada em Enfermagem Oncológica pela Faculdade Inesp, Pós-graduada em Enfermagem do Trabalho pela Faculdade Venda Nova do Imigrante - FAVENI.

${ }^{3}$ Enfermeira Graduada pela Universidade Estadual de Feira de Santana (UEFS), Mestre em Saúde Coletiva pela UEFS < Doutoranda em Saúde Coletiva pela UEFS, Professora Assistente da UEFS, Departamento de Saúde, Colegiado de Enfermagem.
} 
on the health of these professionals. Conclusion: emergency nurses in Brazil are exposed to working conditions that were characterized as unfavorable and precarious, which have a direct and negative impact on the health of these professionals.

Descriptors: Working Conditions; Nurses; Emergencies.

\section{RESUMEN}

Objetivo: caracterizar las condiciones de trabajo de las enfermeras de emergencia en el escenario brasileño e identificar cómo estas condiciones influyen en la salud de estos trabajadores. Método: revisión integradora, con una encuesta en línea realizada en junio de 2020 en el portal de la Biblioteca Virtual en Salud, en la Base de Datos de Literatura y Ciencias de la Salud de América Latina y el Caribe, utilizando los descriptores: condiciones de trabajo Y enfermeras Y emergencias. Se obtuvieron 16 artículos, los cuales fueron analizados mediante Análisis de Contenido Temático. Resultados: las condiciones de trabajo de las enfermeras de emergencia se han caracterizado por la existencia de un espacio físico inadecuado, largas horas de trabajo, falta de insumos y recursos humanos, lo que tiene un impacto negativo en la salud de estos profesionales. Conclusión: las enfermeras de emergencia en Brasil están expuestas a condiciones de trabajo que se caracterizaron como desfavorables y precarias, que tienen un impacto directo y negativo en la salud de estos profesionales.

Descriptores: Condiciones de Trabajo; Enfermeras y Enfermeros; Urgencias Médicas.

\section{INTRODUÇÃO}

O processo de trabalho do enfermeiro é caracterizado por ser assistencialgerencial, englobando a realização de procedimentos assistenciais considerados de maior complexidade técnica, bem como a coordenação do processo de trabalho em saúde/enfermagem e a gestão dos serviços de saúde. ${ }^{1}$

Especificamente acerca do trabalho de enfermeiros nos serviços de emergência, observa-se a busca de estratégias para superar um ambiente permeado pela procura constante de atendimento. Mesmo com a implantação e avanço do Sistema Único de Saúde (SUS) e da Política Nacional de Atenção às Urgências (PNAU), que visam a descentralização dos serviços de urgências/emergências, os serviços hospitalares continuam sendo locais com maiores demandas de atendimentos emergenciais e porta de entrada aos serviços de saúde, até em situações que poderiam ser resolvidas, do ponto de vista clínico, na atenção básica. $^{2}$

Sabe-se a importância das condições de trabalho para os enfermeiros, a fim de que estes realizem o seu processo produtivo. Em linhas gerais, entende-se condições de trabalho como um conjunto de variáveis que influenciam o trabalho, a vida do trabalhador e a atividade por ele executada e que são relativas à relação entre o trabalhador e seu ambiente de trabalho, incluindo instrumentos, métodos e organização. $^{3}$

Pode-se citar como exemplo: as condições do ambiente de trabalho, a 
quantidade e qualidade dos materiais disponíveis, a capacidade do trabalhador para utilizá-los, as verbas destinadas à aquisição dos instrumentos de trabalho, o dimensionamento de pessoal, os riscos aos quais o trabalhador está exposto, o salário pago ao trabalhador diante de sua jornada de trabalho, a satisfação com o trabalho, o convívio no ambiente de trabalho, os condicionantes ergonômicos, entre outros. ${ }^{3}$

Estudos $^{3,4}$ apontam que as condições de trabalho do enfermeiro são inadequadas por diversas razões, a saber: desgaste físico e emocional; baixos salários; baixo valor econômico e social do trabalho; multiplicidade de vínculos e de jornada de trabalho; ritmo de trabalho longo e intenso; ambiente de trabalho precário, com disponibilização insuficiente de insumos e materiais imprescindíveis ao atendimento das necessidades de saúde dos usuários.

As condições de trabalho desfavoráveis em que os enfermeiros muitas vezes estão expostos no Brasil são influenciadas pela política neoliberal, onde o setor de saúde é submetido à rígida contenção de custos. $^{5}$ Tais condições podem resultar em doenças ocupacionais, entre as quais as mais prevalentes são: infarto agudo do miocárdio, distúrbios mentais neurológicos, psiquiátricos, síndromes depressivas, síndrome do pânico, hipertensão, gastrite, doenças somáticas, Síndrome de Burnout, entre outras. ${ }^{6}$
Deste modo, este estudo tem como objetivo caracterizar as condições de trabalho nas quais os enfermeiros emergencistas estão expostos no cenário brasileiro e identificar como essas condições influenciam na saúde desses trabalhadores.

\section{MÉTODO}

Trata-se de uma revisão integrativa de literatura, a qual se constitui em um método que tem como finalidade realizar a sintetização dos resultados obtidos em pesquisas sobre determinado tema ou questão, fornecendo informações sobre um assunto/problema, constituindo um corpo de conhecimento direcionado para revisão de teorias ou definição de conceitos. ${ }^{7}$

$\mathrm{O}$ estudo seguiu as etapas propostas por Botelho, Cunha e Macedo ${ }^{7}$. $\mathrm{Na}$ primeira etapa, definiu-se o objeto a ser estudado a partir da identificação do tema e da seleção das questões de pesquisa “Quais são as condições de trabalho nas quais os enfermeiros emergencistas estão expostos no cenário brasileiro? Como essas condições de trabalho influenciam na saúde desses trabalhadores?", bem como os descritores a serem utilizados na busca online.

O levantamento online das produções científicas ocorreu no período de 18 a 30 de junho de 2020, no portal de periódicos eletrônicos oferecido pela 
Biblioteca Virtual em Saúde (BVS). Esta plataforma de pesquisa virtual disponibiliza produções científicas de periódicos de renome nacionais e internacionais.

Para a realização da busca, foram utilizados os seguintes descritores em português: condições de trabalho, enfermeiros e emergência, valendo-se do recurso de operador booleano AND a fim de 'filtrar' artigos com esta temática e atender aos objetivos da pesquisa. Os descritores foram então agrupados do seguinte modo: condições de trabalho AND enfermeiros AND emergência.

$\mathrm{Na}$ segunda etapa, foram estabelecidos os critérios de inclusão e exclusão das produções científicas a serem analisadas, tendo sido definidos os seguintes critérios de inclusão: documentos na modalidade de artigos publicados no período de 2013 a 2020 (com vistas a caracterizar as condições de trabalho de enfermeiros emergencistas em publicações mais recentes), em português, disponíveis online na íntegra nas bases de dados Literatura Latino-Americana e do Caribe em Ciências da Saúde (LILACS) e Banco de Dados em Enfermagem (BDENF). Salienta-se que os descritores utilizados para a busca na BVS, apresentados na primeira etapa, foram os mesmos condições de trabalho AND enfermeiros AND emergência - e em português, pois, buscou-se analisar a realidade brasileira, a Rev Enferm Atenção Saúde [Online]. Ago/Dez 2020; 9(2):95-110 partir dos artigos publicados em português, sendo selecionadas na BVS as duas bases de dados pesquisadas - LILACS e BDENF.

Tais critérios de inclusão foram colocados no recurso 'Configurar Filtro', disponível na página da BVS, sendo que após clicar em cada um desses itens, era acionado o ícone 'Filtrar' para possibilitar a seleção de artigos a serem analisados. Foram considerados critérios de exclusão artigos que não contemplassem os objetivos do estudo ou que não estivessem disponíveis em sua versão completa.

Deste modo, ao final da primeira busca, foram identificados 33 artigos, dos quais 11 foram repetidos, restando 22 produções diferentes.

$\mathrm{Na}$ terceira etapa, realizou-se uma leitura dos resumos, sendo excluídos, novamente, seis artigos, pois não atendiam ao objetivo e à questão proposta nesta produção, totalizando, assim, 16 artigos, que compuseram o corpus deste estudo.

$\mathrm{Na}$ quarta etapa, procedeu-se à categorização dos estudos selecionados, após uma leitura aprofundada dos 16 artigos para obtenção de informações relevantes ao estudo. Para tanto, foi construído o Quadro 1, com a caracterização dos artigos, considerando os aspectos como autor(es), objetivo(s), resultados e local/ ano. Neste momento, emergiram as seguintes categorias empíricas: Condições de trabalho dos enfermeiros nos serviços de emergência 
e Interferência das condições de trabalho na saúde dos enfermeiros emergencistas.

$\mathrm{Na}$ quinta etapa, procedeu-se à análise e interpretação dos resultados, a partir da análise dos artigos, corpus da revisão integrativa, pelo método Análise de Conteúdo Temática na perspectiva de Minayo $^{12}$, permitindo a definição das categorias temáticas. Os artigos selecionados foram inicialmente lidos na íntegra, com posterior elaboração de seleção de unidades da análise - unidades temáticas; por fim, os estudos foram categorizados. A análise temática foi realizada a partir das seguintes fases: pré- análise, exploração do material, tratamento dos resultados obtidos e interpretação. ${ }^{8}$

Ao final, na sexta etapa, desenvolveu-se a apresentação da revisão propriamente dita, bem como a síntese do conhecimento, apresentada nas discussões deste estudo.

\section{RESULTADOS}

$\mathrm{Na}$ primeira busca foi encontrado um total de 131 produções científicas, fazendo-se necessário a utilização de 'filtros' para se atingir publicações mais específicas sobre o objetivo do artigo.

Figura 1: Esquema de seleção de artigos na BVS para construção da Revisão Integrativa, jun., 2020.

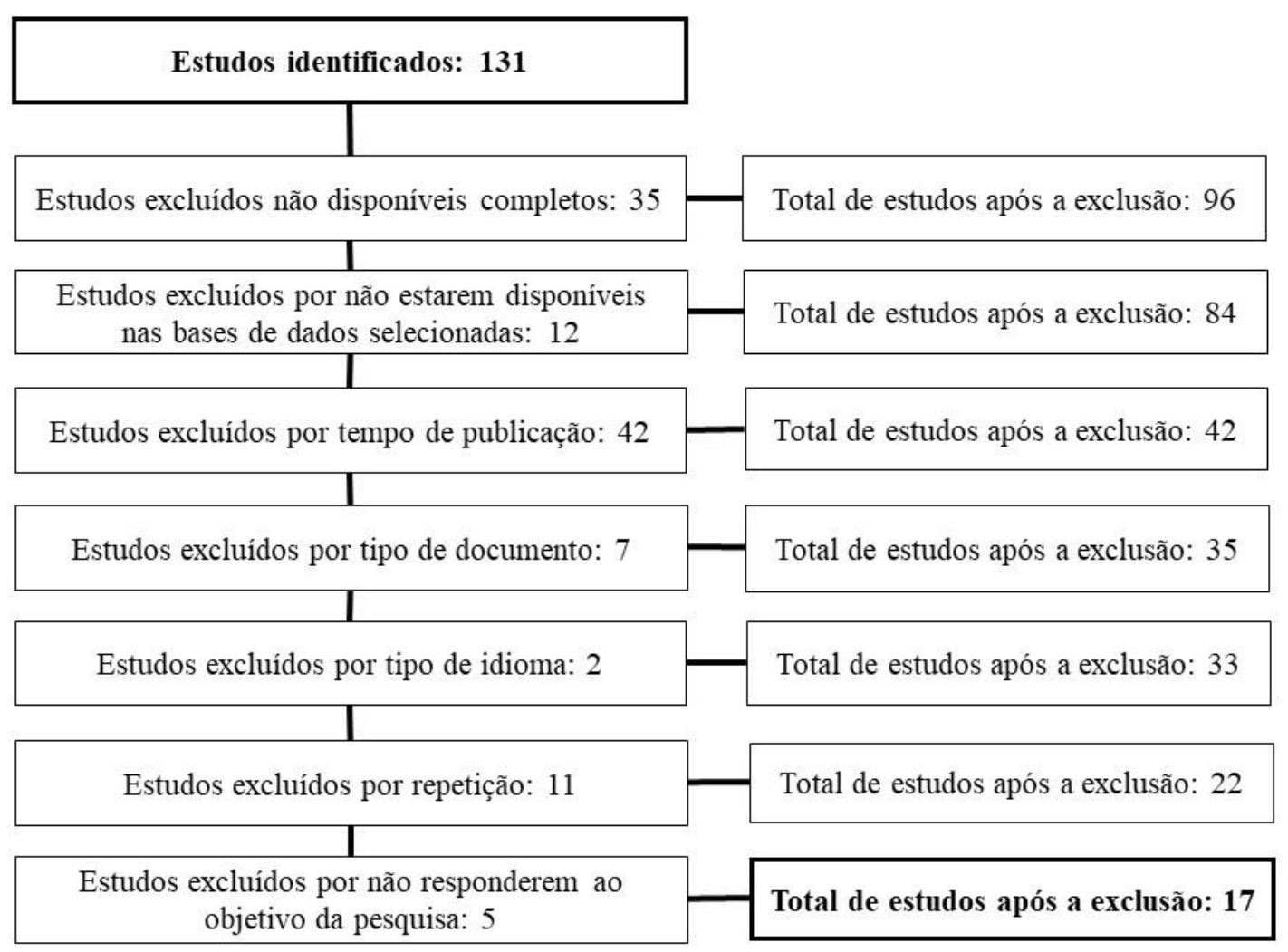


Após essa seleção e leitura criteriosa

dos resumos dos artigos encontrados,

obteve-se um total de 16 produções científicas correlacionadas com o tema

estudado, as quais foram utilizadas na

revisão.

Quadro 1: Síntese das produções científicas incluídas na Revisão Integrativa (2013-2020) (BVS, jun.2020).

\begin{tabular}{|c|c|c|c|}
\hline Autor & Objetivo(s) & Resultados & Local/Ano \\
\hline $\begin{array}{l}\text { 1) } \\
\text { Mendes et al. }\end{array}$ & $\begin{array}{l}\text { Investigar as motivações } \\
\text { para o trabalho e avaliar } \\
\text { as condições de trabalho } \\
\text { oferecidas aos } \\
\text { enfermeiros e médicos } \\
\text { no atendimento aos } \\
\text { usuários em serviços de } \\
\text { emergência. }\end{array}$ & $\begin{array}{l}\text { Na avaliação das motivações ficou evidenciado o } \\
\text { fator Realização Profissional como o de maior } \\
\text { importância e o Prestígio como o de menor } \\
\text { relevância. Em relação às condições de trabalho } \\
\text { oferecidas pelas emergências, as opiniões dos } \\
\text { enfermeiros e médicos majoritariamente } \\
\text { consideram "Ruim" e "Regular" (Revista } \\
\text { Brasileira de Enfermagem). }\end{array}$ & $\begin{array}{l}\text { Recife-PE/ } \\
2013\end{array}$ \\
\hline $\begin{array}{l}\text { 2) } \\
\text { Oliveira et al. }\end{array}$ & $\begin{array}{l}\text { Identificar, na visão do } \\
\text { enfermeiro, os riscos } \\
\text { psicossociais presentes } \\
\text { em serviço de } \\
\text { emergência e analisar } \\
\text { como esses riscos afetam } \\
\text { a saúde do grupo. }\end{array}$ & $\begin{array}{l}\text { Os riscos psicossociais identificados acarretam } \\
\text { estresse ocupacional, sendo alguns deles: } \\
\text { insuficiência de recursos humanos e materiais, } \\
\text { ambiguidade de papéis e violência (Brazilian } \\
\text { Journal of Nursing). }\end{array}$ & $\begin{array}{l}\text { Rio de } \\
\text { Janeiro-RJ/ } \\
2013\end{array}$ \\
\hline $\begin{array}{l}\text { 3) } \\
\text { Sobral et al. }\end{array}$ & $\begin{array}{l}\text { Realizar uma revisão } \\
\text { sistemática acerca da } \\
\text { assistência de } \\
\text { enfermagem nas } \\
\text { unidades de urgência e } \\
\text { emergência no período } \\
\text { de } 2005 \text { a } 2009 \text {. }\end{array}$ & $\begin{array}{l}\text { Os resultados evidenciaram que os serviços de } \\
\text { emergência se constituem em ambiente de } \\
\text { trabalho com condições limítrofes que interferem } \\
\text { nos aspectos emotivos e físicos, destacando o } \\
\text { estresse como uma consequência desse processo. } \\
\text { Nestes espaços, cada vez mais o enfermeiro vem } \\
\text { assumindo posições de destaque na prestação de } \\
\text { cuidados a pacientes em situações emergenciais e } \\
\text { vem sendo apontado como o profissional } \\
\text { apropriado para assumir a gerência de casos e } \\
\text { situações de urgência e emergência, graças às } \\
\text { habilidades que possuem. Contudo, muitos desses } \\
\text { profissionais se encontram despreparados para } \\
\text { atuar em serviços de urgência e emergência, o que } \\
\text { justifica a necessidade de maiores investimentos } \\
\text { na capacitação, treinamento e qualificação nessa } \\
\text { área por parte das instituições e órgãos } \\
\text { competentes (Revista de Pesquisa). }\end{array}$ & $\begin{array}{l}\text { Revisão } \\
\text { sistemática } \\
\text { / } 2013\end{array}$ \\
\hline $\begin{array}{l}\text { 4) } \\
\text { Martins et al. }\end{array}$ & $\begin{array}{l}\text { Identificar o significado } \\
\text { que os enfermeiros de } \\
\text { uma Unidade de Pronto } \\
\text { Socorro/Emergência } \\
\text { atribuem às cargas de } \\
\text { trabalho e revelar as } \\
\text { cargas vivenciadas no } \\
\text { ambiente de trabalho. }\end{array}$ & $\begin{array}{l}\text { Constatou-se que a maioria dos sujeitos conhece } \\
\text { as cargas psicológicas e biológicas e apenas um } \\
\text { mencionou as cargas químicas a que estão } \\
\text { expostos no ambiente de trabalho. Entretanto, os } \\
\text { enfermeiros não identificaram a carga mecânica e } \\
\text { confundiram a carga física com a fisiológica, } \\
\text { evidenciando a ausência ou falha no processo de } \\
\text { capacitação dos trabalhadores em questão, tão } \\
\text { necessário para que adquiram conhecimento sobre } \\
\text { os efeitos maléficos dessas cargas à saúde } \\
\text { (Ciência, Cuidado e Saúde). }\end{array}$ & $\begin{array}{l}\text { Londrina- } \\
\text { PR/ } 2013\end{array}$ \\
\hline $\begin{array}{l}\text { 5) } \\
\text { Fonseca e } \\
\text { Lopes Neto }\end{array}$ & $\begin{array}{l}\text { Identificar os níveis de } \\
\text { estresse, as áreas e suas } \\
\text { respectivas atividades } \\
\text { apontadas como }\end{array}$ & $\begin{array}{l}\text { Os enfermeiros estavam em risco para alto nível } \\
\text { de estresse. O Funcionamento da unidade, } \\
\text { condições de trabalho e administração de pessoal } \\
\text { foram as áreas mais estressoras. A solicitação de }\end{array}$ & $\begin{array}{l}\text { Manaus- } \\
\text { AM/ } 2014\end{array}$ \\
\hline
\end{tabular}




\begin{tabular}{|c|c|c|c|}
\hline & $\begin{array}{l}\text { estressoras pelos } \\
\text { enfermeiros de unidades } \\
\text { de emergência. }\end{array}$ & $\begin{array}{l}\text { revisão e conserto de equipamento foi a atividade } \\
\text { mais estressora (Revista da Rede de Enfermagem } \\
\text { do Nordeste). }\end{array}$ & \\
\hline $\begin{array}{l}\text { 6) } \\
\text { Zandomenighi } \\
\text { et al. }\end{array}$ & $\begin{array}{l}\text { Identificar os desafios, } \\
\text { principalmente as } \\
\text { dificuldades, do cuidado } \\
\text { prestado aos pacientes } \\
\text { graves no Serviço } \\
\text { Hospitalar de } \\
\text { Emergência (SHE) do } \\
\text { Hospital Escola sob o } \\
\text { ponto de vista dos } \\
\text { enfermeiros e listar } \\
\text { estratégias de solução do } \\
\text { problema sugeridas pela } \\
\text { população estudada. }\end{array}$ & $\begin{array}{l}\text { As principais dificuldades relatadas foram em } \\
\text { relação ao déficit de recursos materiais, humanos } \\
\text { e físicos frente à grande demanda de pacientes } \\
\text { graves, havendo dificuldade na manutenção da } \\
\text { privacidade do paciente e na manipulação de } \\
\text { equipamentos como ventilador mecânico. A } \\
\text { principal interferência na rotina do setor com a } \\
\text { presença do paciente crítico foi em relação ao } \\
\text { dimensionamento de pessoal. As principais } \\
\text { estratégias sugeridas foram: aumentar os leitos de } \\
\text { UTI, contratar mais funcionários, realizar mais } \\
\text { treinamentos com a equipe e agrupar os pacientes } \\
\text { graves (Revista Mineira de Enfermagem). }\end{array}$ & $\begin{array}{l}\text { Londrina- } \\
\text { PR/ } 2014\end{array}$ \\
\hline $\begin{array}{l}\text { 7) } \\
\text { Mesquita et al. }\end{array}$ & $\begin{array}{l}\text { Analisar a visão do } \\
\text { gestor/enfermeiro sobre } \\
\text { necessidade de } \\
\text { implementar o apoio } \\
\text { psicológico aos } \\
\text { profissionais. }\end{array}$ & $\begin{array}{l}\text { Apesar de não terem realizado uma avaliação do } \\
\text { nível de estresse nos profissionais, os resultados } \\
\text { apontam que os enfermeiros/ gestores consideram } \\
\text { importante implementar estratégias de apoio } \\
\text { psicológico, as quais podem favorecer a qualidade } \\
\text { de vida dessas pessoas, bem como refletir em } \\
\text { melhor desempenho nas atividades cotidianas } \\
\text { (Revista de Enfermagem do Centro Oeste } \\
\text { Mineiro). }\end{array}$ & $\begin{array}{l}\text { Araguaína, } \\
\text { Gurupi e } \\
\text { Palmas- } \\
\text { TO/ } 2014\end{array}$ \\
\hline $\begin{array}{l}8) \\
\text { Silva et al. }\end{array}$ & $\begin{array}{l}\text { Conhecer as principais } \\
\text { dificuldades vivenciadas } \\
\text { pela equipe de saúde que } \\
\text { atua em um serviço de } \\
\text { atendimento móvel de } \\
\text { urgência na percepção da } \\
\text { equipe de enfermagem. }\end{array}$ & $\begin{array}{l}\text { Os resultados apontaram dificuldades enfrentadas } \\
\text { pela equipe de saúde que atua em um serviço de } \\
\text { atendimento móvel de urgência na percepção dos } \\
\text { enfermeiros e técnicos de enfermagem, bem como } \\
\text { foi possível identificar possíveis estratégias que } \\
\text { potencializem a melhora do serviço (Revista de } \\
\text { Enfermagem do Centro Oeste Mineiro). }\end{array}$ & $\begin{array}{l}\text { Rio } \\
\text { Grande do } \\
\text { Sul-RS/ } \\
2014\end{array}$ \\
\hline $\begin{array}{l}\text { 9) } \\
\text { Rosado, Russo } \\
\text { e Maia }\end{array}$ & $\begin{array}{l}\text { Analisar a relação entre o } \\
\text { exercício profissional } \\
\text { nos hospitais públicos de } \\
\text { urgência e emergência e } \\
\text { as situações de saúde- } \\
\text { adoecimento dos sujeitos } \\
\text { que o executam, } \\
\text { considerando as } \\
\text { múltiplas determinações } \\
\text { desse processo. }\end{array}$ & $\begin{array}{l}\text { Os sujeitos reconhecem a importância do trabalho } \\
\text { para garantia de condições favoráveis à saúde. } \\
\text { Entretanto, destacam seus efeitos no desgaste } \\
\text { físico e psíquico dos trabalhadores, por } \\
\text { impulsionar estresse, ausência de hábitos } \\
\text { saudáveis, hipertensão arterial, distúrbios do sono, } \\
\text { osteomusculares e gastrintestinais (Revista } \\
\text { Ciência \& Saúde Coletiva). }\end{array}$ & $\begin{array}{l}\text { Natal e } \\
\text { Mossoró- } \\
\text { RN/ } 2015\end{array}$ \\
\hline $\begin{array}{l}\text { 10) } \\
\text { Oliveira, } \\
\text { Mazzaia e } \\
\text { Marcolan }\end{array}$ & $\begin{array}{l}\text { Verificar se os } \\
\text { enfermeiros do serviço } \\
\text { hospitalar de emergência } \\
\text { apresentavam sintomas } \\
\text { depressivos, identificar } \\
\text { fatores intervenientes e } \\
\text { analisar a percepção } \\
\text { sobre o sofrimento } \\
\text { psíquico relatado e a } \\
\text { influência na assistência } \\
\text { prestada. }\end{array}$ & $\begin{array}{l}\text { Participaram } 23 \text { enfermeiros, dos quais } 91,3 \% \\
\text { apresentaram sintomas de depressão. Fatores para } \\
\text { adoecimento estavam relacionados às condições } \\
\text { do trabalho como sobrecarga, desvalorização, } \\
\text { falta de recursos humanos e materiais. A maioria } \\
\text { dos enfermeiros não percebia o próprio } \\
\text { sofrimento psíquico, não o relacionava às } \\
\text { condições de trabalho e acreditava não haver } \\
\text { influência desse sofrimento na assistência } \\
\text { prestada (Acta Paulista de Enfermagem). }\end{array}$ & $\begin{array}{l}\text { Presidente } \\
\text { Prudente- } \\
\text { SP/ } 2015\end{array}$ \\
\hline $\begin{array}{l}\text { 11) } \\
\text { Worm et al. }\end{array}$ & $\begin{array}{l}\text { Identificar os fatores de } \\
\text { risco ao adoecimento } \\
\text { relacionado ao trabalho } \\
\text { de enfermagem em } \\
\text { Serviço de Atendimento } \\
\text { Móvel de Urgência. }\end{array}$ & $\begin{array}{l}\text { Na avaliação do contexto de trabalho, a } \\
\text { organização do trabalho foi apontada como } \\
\text { crítica. Os Indicadores Prazer e Sofrimento no } \\
\text { Trabalho apontaram liberdade de expressão dos } \\
\text { profissionais. Por outro lado, há falta de } \\
\text { reconhecimento e esgotamento profissional. Para }\end{array}$ & $\begin{array}{l}\text { Santa } \\
\text { Catarina- } \\
\text { SC/ } 2016\end{array}$ \\
\hline
\end{tabular}




\begin{tabular}{|c|c|c|c|}
\hline & & $\begin{array}{l}\text { a avaliação dos danos relacionados ao trabalho, } \\
\text { destacam-se os danos físicos (Revista Cuidarte). }\end{array}$ & \\
\hline $\begin{array}{l}\text { 12) } \\
\text { Roncalli et al. }\end{array}$ & $\begin{array}{l}\text { Compreender a vivência } \\
\text { do enfermeiro que atua } \\
\text { na classificação de risco } \\
\text { de uma Unidade de } \\
\text { Pronto Atendimento } \\
\text { (UPA). }\end{array}$ & $\begin{array}{l}\text { O cotidiano na UPA é expresso na elevada } \\
\text { demanda e nas reclamações dos usuários. Retrata } \\
\text { um ambiente estressante e conflituoso pela espera } \\
\text { e pelo sofrimento de cada um que aguarda o } \\
\text { atendimento. Além das ações assistenciais, as } \\
\text { gerenciais e educacionais acarretam sobrecarga de } \\
\text { trabalho no cotidiano do enfermeiro (Revista de } \\
\text { Enfermagem UFPE). }\end{array}$ & $\begin{array}{l}\text { Belo } \\
\text { Horizonte- } \\
\text { MG/ } 2017\end{array}$ \\
\hline $\begin{array}{l}\text { 13) } \\
\text { Silva et al. }\end{array}$ & $\begin{array}{l}\text { Avaliar a presença de } \\
\text { distúrbios } \\
\text { osteomusculares em } \\
\text { enfermeiros das } \\
\text { Unidades de Pronto } \\
\text { Atendimento de uma } \\
\text { capital da região norte do } \\
\text { Brasil. }\end{array}$ & $\begin{array}{l}\text { Evidenciou-se que todos os participantes tiveram } \\
\text { pelo menos um sintoma de dor ou desconforto } \\
\text { musculoesquelético nos últimos } 12 \text { meses. A } \\
\text { região pescoço/região cervical apresentou maior } \\
\text { incidência }(60,0 \%) \text {, seguida da dor lombar } \\
(54,3 \%) \text { (Revista de Enfermagem e Atenção à } \\
\text { Saúde). }\end{array}$ & $\begin{array}{l}\text { Local do } \\
\text { estudo não } \\
\text { identifica- } \\
\text { do/ } 2017\end{array}$ \\
\hline $\begin{array}{l}\text { 14) } \\
\text { Santos et al. }\end{array}$ & $\begin{array}{l}\text { Descrever os fatores } \\
\text { estressores para a equipe } \\
\text { de enfermagem do setor } \\
\text { de emergência de um } \\
\text { hospital público. }\end{array}$ & $\begin{array}{l}\text { Os profissionais da equipe de enfermagem da } \\
\text { Emergência estão expostos a fatores de riscos } \\
\text { psicológicos, inclusive ao estresse ocupacional, } \\
\text { devido à sobrecarga de trabalho, à demanda maior } \\
\text { do que as condições assistenciais da equipe e ao } \\
\text { número insuficiente de profissionais da } \\
\text { enfermagem no setor (Revista online de Pesquisa } \\
\text { Cuidado é Fundamental). }\end{array}$ & $\begin{array}{l}\text { Jequié- } \\
\text { BA/2019 }\end{array}$ \\
\hline $\begin{array}{l}\text { 15) } \\
\text { Cordeiro et al. }\end{array}$ & $\begin{array}{l}\text { Investigar a satisfação } \\
\text { profissional de } \\
\text { enfermeiros em uma } \\
\text { unidade de emergência } \\
\text { de um hospital da Zona } \\
\text { Norte do Ceará. }\end{array}$ & $\begin{array}{l}\text { Os profissionais mostraram-se satisfeitos com o } \\
\text { seu desempenho no trabalho pelo sentimento de } \\
\text { ajuda ao próximo, porém, ainda se obteve relatos } \\
\text { de insatisfação como o desgaste físico e } \\
\text { emocional (Nursing). }\end{array}$ & $\begin{array}{l}\text { Zona } \\
\text { Norte-CE/ } \\
2019\end{array}$ \\
\hline $\begin{array}{l}\text { 16) } \\
\text { Marques et al. }\end{array}$ & $\begin{array}{l}\text { Identificar os fatores que } \\
\text { motivam a satisfação e } \\
\text { insatisfação no trabalho } \\
\text { de enfermeiros. }\end{array}$ & $\begin{array}{l}\text { Emergiram-se após análise duas categorias: } \\
\text { Fatores que motivam a insatisfação no trabalho e } \\
\text { Fatores que motivam a satisfação no trabalho. } \\
\text { Relacionou-se a insatisfação ao número } \\
\text { insuficiente de recursos humanos e materiais e à } \\
\text { falta de valorização da sociedade do enfermeiro; } \\
\text { já a satisfação esteve associada com a } \\
\text { oportunidade de capacitação e as reuniões do } \\
\text { serviço (Revista de Enfermagem UFPE). }\end{array}$ & $\begin{array}{l}\text { Local do } \\
\text { estudo não } \\
\text { identifica- } \\
\text { do/ } 2020\end{array}$ \\
\hline
\end{tabular}

Das 16 produções científicas selecionadas, uma trata-se de artigo de revisão, sendo 15 artigos originais, dos quais oito foram estudos com abordagem qualitativa, seis quantitativa (quatro estudo transversal) e um quantiqualitativa. Observa-se que, do total dos artigos selecionados, o periódico com maior número de publicações é a Revista de Enfermagem do Centro Oeste Mineiro e a Revista de Enfermagem UFPE, totalizando dois artigos cada, e a região com maior número de estudos é a região Sul e Nordeste, com quatro artigos cada. No que diz respeito ao ano de publicação selecionado, a maioria dos artigos foram 
publicados nos anos de 2013 e 2014, com quatro artigos cada ano, sendo que em 2015, 2017 e 2019 foram encontrados dois artigos e nos anos de 2016 e 2020 um artigo.

Em linhas gerais, conforme apresentado no Quadro 1, os artigos analisados apresentaram uma abordagem relativa às condições de trabalho dos enfermeiros nos serviços de emergência ${ }^{9-19}$, bem como desenvolveram uma discussão sobre a interferência das condições de trabalho na saúde dos enfermeiros emergencistas. ${ }^{9-11,15,17-24}$ Além disso, a partir dos resultados de alguns artigos analisados $^{9-11,15,17-19}$ foi possível identificar aspectos referentes tanto às condições de trabalho dos enfermeiros nos serviços de emergência, quanto à interferência dessas condições de trabalho na saúde destes profissionais.

\section{DISCUSSÃO}

\section{Condições de trabalho dos enfermeiros nos serviços de emergência}

No que tange à qualidade do ambiente físico, equipamentos e materiais disponibilizados para executarem seu trabalho, as condições de trabalho dos enfermeiros emergencistas no Brasil, na grande maioria das vezes, são apontadas como desfavoráveis nos estudos analisados.
O contexto de precarização está inerente ao trabalho dos enfermeiros, tendo como fatores atenuantes a inadequação das estruturas físicas, baixos salários, inexistência de planejamento ergonômico, relações autoritárias, indisponibilidade de equipamentos e materiais, organização do ambiente, insalubridade, longas jornadas de trabalho e alta demanda de atendimentos. ${ }^{9,10,17,19}$

Compreende-se que essas condições de trabalho envolvem variáveis que influenciam o trabalho, a vida do trabalhador e a atividade que ele executa, a exemplo da autonomia, flexibilização, satisfação, estabilidade no emprego e o atendimento às necessidades de cunho pessoal, como saúde, educação, segurança, moradia e alimentação. ${ }^{3}$

$\mathrm{O}$ enfermeiro que atua em emergência assume fundamental importância na qualidade da assistência, com exigências de cunho técnico, organizacional e relacional, sendo um dos profissionais responsáveis por lidar com situações de imprevisibilidade clínica dos pacientes, precisando administrar recursos materiais, humanos e infraestrutura que permitam a atuação da equipe no atendimento emergencial. Todavia, a (des)configuração do trabalho no contexto de precarização fere a dignidade profissional frente às limitações impostas. ${ }^{11}$ 
Vale ressaltar que, por vezes, a precarização do trabalho do enfermeiro é consequência de um baixo poder de resistência e frágil organização política, o que dificulta a luta por melhorias nas suas condições de trabalho e na sua valorização econômica e social. ${ }^{3}$

A principal dificuldade no processo de trabalho dos enfermeiros emergencistas é a insuficiência na quantidade e qualidade dos materiais destinados ao atendimento dos pacientes graves, o que ocasiona interrupções na assistência aos usuários, verificando-se que se faz preciso uma prática de adaptação e improvisação de materiais e equipamentos, levando a um distanciamento entre o trabalho prescrito e o trabalho real. ${ }^{12}$

Do mesmo modo, estudo realizado por Santos et al. $^{2}$, que buscou analisar as características do ambiente de trabalho do enfermeiro em um serviço hospitalar de emergência, apontou as características desfavoráveis do controle dos enfermeiros sobre o ambiente de trabalho, ao evidenciar como principais dificuldades a superlotação, a falta de recursos e o número insuficiente de profissionais para realizar o trabalho, o que influencia e compromete a capacidade assistencial do serviço e a continuidade do cuidado.

Há ainda que se considerar o fato de que a falta e escassez de materiais e equipamentos leva a situações de conflito na equipe e estresse na tentativa de se desempenhar suas atividades, ${ }^{13}$ bem como se constituem em fatores que provocam a insatisfação no trabalho do enfermeiro. ${ }^{19}$

Relacionado ao espaço físico, cabe destacar que o improviso e a desorganização acabam por gerar limitações na execução de atividades corriqueiras, podendo ser atribuído a ambulâncias sucateadas, a locais com pouca ventilação e temperaturas inadequadas. ${ }^{14}$ Ressalta-se também a falta de reestruturação do espaço físico para atender a crescente procura por atendimentos, obrigando trabalhadores a contínuas improvisações e adaptações, como, por exemplo, em corredores, para o cuidado dos usuários dos serviços de saúde. ${ }^{11}$

As limitações de recursos físicos e materiais disponíveis e condições de trabalho inadequadas para o atendimento podem gerar desmotivação, sobrecarga física e psíquica aos trabalhadores. Tais fatores podem interferir na qualidade da prestação do serviço, o que aponta para a necessidade de investimentos para melhoraria dessas condições, buscando-se efetivar a satisfação dos profissionais com o trabalho, assim como a qualidade do cuidado ofertado no serviço de emergência. $^{25}$

A forma como o trabalho é organizado nos serviços de urgência e emergência, a existência de rotinas 
extenuantes, as cobranças de superiores, a sobrecarga de trabalho e os baixos salários têm também caracterizado as condições de trabalho do enfermeiro emergencista. ${ }^{18}$

Uma particularidade do serviço de emergência é a caracterização de atendimentos de quadros clínicos e/ou traumáticos de diferentes complexidades. Porém, a desinformação dos usuários sobre o tipo de serviço ofertado pode gerar uma desorganização na rotina, diminuindo a resolutividade da assistência por descaracterizar o serviço. ${ }^{14-15}$

Apesar da triagem (acolhimento) realizada pelo enfermeiro na porta de entrada do serviço de saúde, observa-se a persistente busca por atendimento a quadros clínicos que deveriam ser direcionados para as unidades de atenção primária ou rede ambulatorial. Esta busca inadequada pelo serviço emergencial acaba acarretando um acionamento da equipe de forma desnecessária, resultando assim em superlotação do serviço, bem como em sobrecarga de trabalho dos profissionais. ${ }^{11,16}$

Assim, é notório que as más condições de trabalho dos enfermeiros emergencistas podem acarretar na precarização em seu processo de trabalho, expondo não apenas estes profissionais a riscos, bem como comprometendo a qualidade da assistência prestada aos usuários dos serviços de saúde.

\section{Interferência das condições de trabalho na saúde dos enfermeiros emergencistas}

A precarização do trabalho na enfermagem, intensificada pela política de ajustes do modelo neoliberal e capitalista, é contrária ao discurso proposto pelo SUS e tem levado ao consumo desmedido das energias físicas e espirituais dos trabalhadores $^{5}$, fazendo com que estes vivenciem sentimentos de insatisfação, desmotivação e desesperança, sem perspectiva de mudança, repercutindo em sua saúde, com expressões como exaustão, cansaço, fardo, depressão, estresse e até mesmo com a Síndrome de Burnout. ${ }^{10-11}$

Ofertar assistência em um contexto permeado por lotação do serviço, precariedade, risco de vida de paciente, falta de tempo de se alimentar e atender suas necessidades corporais e metabólicas, constituem uma susceptibilidade do profissional frente à possibilidade de prejudicar seu estado de saúde, seja de modo físico e/ou emocional. ${ }^{15,20}$

A sobrecarga de trabalho, a demanda maior do que as condições assistenciais da equipe, bem como $o$ número insuficiente de profissionais da enfermagem no setor, podem ocasionar a exposição a fatores de riscos psicológicos, ao desgaste físico e emocional, inclusive ao estresse ocupacional, o que pode colaborar 
para a diminuição do estímulo para exercer suas funções e sentimento de impotência. ${ }^{17-}$ 19

Segundo estudo realizado por Moraes Filho e Almeida ${ }^{6}$, o profissional de enfermagem está cada vez mais sujeito ao adoecimento ocupacional devido ao estresse no ambiente de trabalho. Sabe-se que a população necessita dos enfermeiros, contudo, estes profissionais também precisam de condições de trabalho/ organizacionais favoráveis para o desempenho de sua função.

Concernente ao desgaste físico, profissionais apresentam problemas cardiovasculares, respiratórios, gastrointestinais, redução da capacidade auditiva, cefaleia, distúrbios do sono, amigdalite, cansaço e principalmente distúrbios osteomoleculares, como lesão por esforço repetitivo, bursite, tendinopatia, dentre outros. ${ }^{9-11}$

Quanto aos desgastes psíquicos associados ao trabalho, manifesta-se a despersonalização, baixa realização pessoal, exaustão emocional, fatores propensos ao desenvolvimento da Síndrome de Burnout, a qual, apesar de multifatorial, apresenta estreita relação com elevados níveis de desgaste e tensão no trabalho..$^{9-11}$

Estudo $^{26}$ realizado em um hospital público de médio porte, localizado no sudoeste baiano, que buscou identificar dimensões sintomatológicas da Síndrome de Burnout em profissionais de enfermagem que atuam em um pronto socorro e acolhimento, demonstrou que uma significativa parcela dos trabalhadores apresenta sintomatologia desta Síndrome, a qual pode estar relacionada ao perfil, rotina e condições de trabalho da emergência, somada à exposição contínua e prolongada aos referidos estressores.

O trabalho pode ser responsável por se constituir fonte de prazer ou de sofrimento, a depender da forma como é realizado, fazendo com que a atuação do enfermeiro emergencista, na maioria das vezes, possa apresentar uma falta de coesão, devido ao excesso de trabalho, implicando em diminuição de horários de repouso, lazer, contato social e familiar, concomitante com suas más condições de trabalho, levando a um grau de insatisfação e desmotivação. ${ }^{21}$

$\mathrm{O}$ estresse profissional pode acabar por influenciar também a vida familiar e privada dos enfermeiros, o que deveria impulsionar as instituições a buscarem estratégias que possam sanar os fatores que conduzem à tensão física ou emocional. ${ }^{22}$ Deste modo, faz-se necessário o desenvolvimento de ações nos ambientes de trabalho que busquem minimizar o efeito desses estressores, buscando promover qualidade aos trabalhadores no desempenho de suas funções e, consequentemente, na assistência prestada aos usuários. 
A redução da carga de trabalho, pausas para descansos, criação de ambientes saudáveis e ergonomicamente adequados, o uso da ginástica laboral para a realização de exercícios de alongamento e relaxamento, avaliação da qualidade de vida e revisão do redimensionamento, constituem-se em propostas para vencer os agravos à saúde dos profissionais decorrentes do trabalho, ${ }^{23,24}$ as quais poderão contribuir para a melhoria das condições laborais e a vivência do trabalhador.

Além disso, estudo realizado por Beleza et al. ${ }^{27}$ acrescenta como medidas que podem contribuir para a saúde ocupacional dos enfermeiros em unidade hospitalar a informação, formação adequada para o trabalho e o seguimento das normatizações. Para tanto, entende-se que é necessário a articulação e participação de gestores e trabalhadores, de modo a proporcionar uma atuação do enfermeiro emergencista livre de riscos para si e para os usuários do serviço.

\section{CONCLUSÃO}

A partir da caracterização das condições de trabalho às quais estão expostos os enfermeiros emergencistas no Brasil percebe-se que estas vêm sendo apontadas como desfavoráveis nas produções científicas analisadas, permeadas pelo processo de precarização que reflete em vários aspectos descritos, como a falta de recursos materiais e humanos, espaço físico inadequado e intensa jornada de trabalho, sendo que tais fatores mencionados repercutem diretamente na saúde desses profissionais.

Essas condições influenciam na saúde dos enfermeiros e é perceptível pelos acometimentos psicológicos, emocionais (insatisfação, desmotivação, desesperança) e físicos (exaustão, cansaço, fardo, depressão, estresse), culminando com a ocorrência de patologias como a Síndrome de Burnout, problemas cardiovasculares, respiratórios, gastrointestinais, distúrbios do sono, entre outros.

Tendo-se em vista os aspectos observados, nota-se a relevância de estudos sobre o processo de trabalho do enfermeiro, principalmente no que compete às condições de trabalho em um contexto de precarização, para que, cientes das mesmas, as instituições invistam em melhorias, sanando as dificuldades, garantindo que os profissionais mantenham sua capacidade funcional preservada, de modo que haja uma melhoria na assistência prestada ao paciente, bem como uma legitimação da força de trabalho dos enfermeiros no campo da saúde.

Dentre as limitações deste estudo destaca-se o fato de ter-se analisado apenas artigos na língua portuguesa. Contudo, 
reitera-se que se buscou caracterizar a realidade brasileira, com as publicações em língua portuguesa, por isso a opção por esse idioma.

\section{REFERÊNCIAS}

1. Leal JAL, Melo CMM. Processo de trabalho da enfermeira em diferentes países: uma revisão integrativa. Rev Bras Enferm. [Internet]. 2018 [citado em 07 dez 2019]; 71(2):413-23.

Disponível em: https://www.scielo.br/pdf/reben/v71n2 /pt_0034-7167-reben-71-02-0413.pdf

2. Santos JLG, Menegon FHA, Pin SB, Erdmann AL, Oliveira RJT, Costa IAP. Ambiente de trabalho do enfermeiro em um serviço hospitalar de emergência. Rev Rene. [Internet]. 2017 [citado em 07 dez 2019]; 18(2):195-203. Disponível em: http://periodicos.ufc.br/rene/article/vie w/19246/29963

3. Silva MC. Condições de trabalho da enfermeira nos hospitais do Sistema Único de Saúde da Bahia. [dissertação] [Internet]. Salvador, BA: Universidade Federal da Bahia; 2017 [citado em 07 dez 2019]. 110p. Disponível em: https://repositorio.ufba.br/ri/bitstream/ ri/24905/1/Dis_Enf_Mariana\%20Cost a\%20da\%20Silva.pdf

4. Braga LM, Torres LM, Ferreira VM. Condições de trabalho e fazer em enfermagem. Rev Enferm UFJF. [Internet]. 2015 [citado em $07 \mathrm{dez}$ 2019]; 1(1):55-63. Disponível em: https://periodicos.ufjf.br/index.php/enf ermagem/article/view/3788/1564

5. Souza MMT, Passos JP, Tavares CMM. Sofrimento e precarização do trabalho em enfermagem. Rev Pesqui (Univ. Fed. Estado Rio J.). [Internet]. 2015 [citado em $07 \mathrm{dez}$ 2019]; 7(1):2072-82. Disponível em: https://www.redalyc.org/pdf/5057/505 750945031.pdf

6. Moraes Filho IM, Almeida RJ. Estresse ocupacional no trabalho em enfermagem no Brasil: uma revisão integrativa. Rev Bras Promoç Saúde. [ Internet]. 2016 [citado em $07 \mathrm{dez}$ 2019]; 29(3):447-54. Disponível em: https://periodicos.unifor.br/RBPS/artic le/view/4645/0

7. Botelho LLR, Cunha CCDA, Macedo M. O método da revisão integrativa nos estudos organizacionais. Gestão e Sociedade [Internet]. 2011 [citado em 07 dez 2019]; 5(11):121-36.

Disponível em: https://www.gestaoesociedade.org/gest aoesociedade/article/view/1220/906

8. Minayo MCS, organizadora. Pesquisa social: teoria, método e criatividade. 29ed. Petrópolis, RJ: Vozes; 2010.

9. Rosado IVM, Russo GHA, Maia EMC. Produzir saúde suscita adoecimento? As contradições do trabalho em hospitais públicos de urgência e emergência. Ciênc Saúde Colet. [Internet]. 2015 [citado em 07 dez 2019]; 20(10):3021-32.

Disponível em: https://www.scielo.br/pdf/csc/v20n10/ 1413-8123-csc-20-10-3021.pdf

10. Mendes ACG, Araújo Júnior JLAC, Furtado BMASM, Duarte PO, Silva ALA, Miranda GMD. Condições e motivações para o trabalho de enfermeiros e médicos em serviços de emergência de alta complexidade. Rev Bras Enferm. [Internet]. 2013 [citado em 07 dez 2019]; 66(2):161-66. Disponível em: https://www.scielo.br/pdf/reben/v66n2 /02.pdf

11. Oliveira EB, Pinel JS, Gonçalves JBA, Diniz DB. Trabalho de enfermagem em emergência hospitalar - riscos psicossociais: pesquisa descritiva. Online Braz J Nurs. [Internet]. 2013 [citado em $07 \mathrm{dez}$ 2019]; 12(1):1-8. Disponível em: 
http://www.objnursing.uff.br/index.ph p/nursing/article/view/4046/pdf_2

12. Zandomenighi RC, Mouro DL, Oliveira CA, Martins EAP. Cuidados intensivos em um serviço hospitalar de emergência: desafios para os enfermeiros. Reme Rev Min Enferm. [Internet]. 2014 [citado em $07 \mathrm{dez}$ 2019]; 18(2):1-10. Disponível em: https://cdn.publisher.gn1.link/reme.org .br/pdf/en_v18n2a12.pdf

13. Martins JT, Bobroff MCC, Ribeiro RP, Robazzi MLCC, Marziale MHP, Haddad MCL. Significados de cargas de trabalho para enfermeiros de pronto socorro/emergência. Ciênc Cuid Saúde. [Internet]. 2013 [citado em 07 dez 2019]; 12(1):40-6. Disponível em: http://periodicos.uem.br/ojs/index.php/ CiencCuidSaude/article/view/16459/p df_134

14. Sobral PHAF, Silva AMP, Santos VEP, Santos RAA, Santos ALS. Atuação de enfermagem em serviços de emergência: revisão sistemática. Rev. Pesqui. (Univ. Fed. Estado Rio J.). [Internet]. 2013 [citado em $07 \mathrm{dez}$ 2019]; 5(4):396-407. Disponível em: http://www.seer.unirio.br/index.php/cu idadofundamental/article/view/1655/p df_893

15. Roncalli AA, Oliveira DN, Melo IC, Viegas SMF, Brito RF. Experiências cotidianas do enfermeiro na classificação de risco em unidade de pronto atendimento. Rev Enferm UFPE. [Internet]. 2017 [citado em 07 dez 2019]; 11(4):1743-51. Disponível em:

https://periodicos.ufpe.br/revistas/revis taenfermagem/article/view/15246/180 30

16. Silva SF, Ilha S, Diefenbach GD, Pereira JC. Dificuldades vivenciadas em um serviço de atendimento móvel de urgência: percepções da equipe de enfermagem. Rev Enferm. Cent.-Oeste Min. [Internet]. 2014 [citado em 07 dez 2019]; 4(2):1161-72. Disponível em: http://www.seer.ufsj.edu.br/index.php/ recom/article/view/541/751

17. Santos JNMO, De La Longuiniere ACF, Vieira SNS, Amaral APS, Sanches GJC, Vilela ABA. Estresse ocupacional: exposição da equipe de enfermagem de uma unidade de emergência. Rev. Pesqui. (Univ. Fed. Estado Rio J.). [Internet]. 2019 [citado em 07 dez 2019]; 11(n esp):455-63. Disponível em: http://www.seer.unirio.br/index.php/cu idadofundamental/article/view/6386/p df_1

18. Cordeiro MG, Torres ARA, Rocha FAA, Costa FBC, Branco JGO. Satisfação profissional de enfermeiros em uma unidade de emergência. Nursing (São Paulo). 2019; 22(249): 2604-9.

19. Marques CR, Ribeiro BMSS, Martins JT, Dias HG, Darli RCMB, Bernardes MLG, Karino, ME. Fatores de satisfações e insatisfações no de enfermeiros. Rev Enferm UFPE on line. [Internet]. 2020 [citado em 07 mai 2020]; 14:e244966. Disponível em:

https://periodicos.ufpe.br/revistas/revis taenfermagem/article/view/244966/35 391

20. Worm FA, Pinto MAO, Schiavenato D, Ascari RA, Trindade LL, Silva OM. Risco de adoecimento dos profissionais de enfermagem no trabalho em atendimento móvel de urgência. Rev Cuid. [Internet]. 2016 2020 [citado em $07 \mathrm{dez} 2019$ ]; 7(2):1288-96. Disponível em: http://www.scielo.org.co/pdf/cuid/v7n 2/v7n2a06.pdf

21. Oliveira FP, Mazzaia MC, Marcolan JF. Sintomas de depressão e fatores intervenientes entre enfermeiros de serviço hospitalar de emergência. Acta Paul Enferm. [Internet]. 2015 [citado em 07 dez 2019]; 28(3):209-15. Disponível em: https://www.scielo.br/pdf/ape/v28n3/1 982-0194-ape-28-03-0209.pdf 
22. Fonseca JRF, Lopes Neto D. Níveis de estresse ocupacional e atividades estressoras em enfermeiros de unidades de emergência. Rev Rene. [Internet]. 2014 [citado em $07 \mathrm{dez}$ 2019]; 15(5):732-42. Disponível em: http://periodicos.ufc.br/rene/article/vie w/3230/2486

23. Silva RF, Silva SF, Almeida NM, Barbosa TC, Quaresma FRP, Maciel ES. Presença de distúrbios osteomusculares em enfermeiros de unidades de pronto atendimento. Rev Enferm Atenção Saúde. [Internet]. 2017 [citado em 07 dez 2019]; 6(2):211. Disponível em: http://seer.uftm.edu.br/revistaeletronic a/index.php/enfer/article/view/2081/pd $\mathrm{f}$

24. Mesquita KL, Gomes GPLA, Silva MJBF, Santos LF. A visão do enfermeiro/gestor sobre a necessidade de implementar apoio psicológico aos profissionais do serviço de atendimento móvel de urgência. Rev Enferm. Cent.-Oeste Min. [Internet]. 2014 [citado em 07 dez 2019]; 4(1): 1019-28. Disponível em: http://www.seer.ufsj.edu.br/index.php/ recom/article/view/453/576

25. Sakai AM, Rossaneis MA, Haddad MCFL, Sardinha DSS. Sentimentos de enfermeiros no acolhimento e na avaliação da classificação de risco em pronto-socorro. Rev Rene. [Internet]. 2016 [citado em 07 dez 2019]; 17(2):233-41. Disponível em: http://periodicos.ufc.br/rene/article/vie w/3007/2323

26. Oliveira LP, Araújo GF. Características da síndrome de burnout em enfermeiros da emergência de um hospital público. Rev Enferm Contemp. [Internet]. 2016 [citado em 07 dez 2019]; 5(1):34-42. Disponível em: https://www5.bahiana.edu.br/index.ph p/enfermagem/article/view/834/645

27. Beleza CMF, Gouveia MTO, Robazzi MLCC, Torres CRD, Azevedo GAV. Riscos ocupacionais e problemas de saúde percebidos por trabalhadores de enfermagem em Unidade Hospitalar. Cienc Enferm. [Internet]. 2013 [citado em 07 dez 2019]; 19(3):73-82.

Disponível em: https://scielo.conicyt.cl/pdf/cienf/v19n 3/art_08.pdf

RECEBIDO: 02/01/2019

APROVADO: $21 / 07 / 2020$

PUBLICADO: $12 / 2020$ 